\title{
The Role of Histone Post- Translational Modifications in Merkel Cell Carcinoma
}

\begin{abstract}
Chiara Mazziotta ${ }^{1,2}$, Carmen Lanzillotti ${ }^{1,2}$, Roberta Gafà ${ }^{3}$, Antoine Touzé ${ }^{4}$, Marie-Alice Durand ${ }^{4}$, Fernanda Martini ${ }^{1,2,5^{* t}}$ and John Charles Rotondo ${ }^{1,2^{*+}}$

${ }^{1}$ Department of Medical Sciences, University of Ferrara, Ferrara, Italy, ${ }^{2}$ Center for Studies on Gender Medicine, Department of Medical Sciences, University of Ferrara, Ferrara, Italy, ${ }^{3}$ Department of Translational Medicine and for Romagna, University of Ferrara, Ferrara, Italy, ${ }^{4}$ ISP "Biologie des infections à polyomavirus" Team, UMR INRA 1282, University of Tours, Tours, France, ${ }^{5}$ Laboratory for Technologies of Advanced Therapies (LTTA), University of Ferrara, Ferrara, Italy
\end{abstract}

OPEN ACCESS

Edited by:

Luis Del Valle,

Louisiana State University,

United States

Reviewed by:

Judy Sue Crabtree,

Louisiana State University,

United States

${ }^{*}$ Correspondence:

John Charles Rotondo

rtnjnc@unife.it

Fernanda Martin

fernanda.martini@unife.it

tORCID:

John Charles Rotondo orcid.org/0000-0001-5179-1525

Fernanda Martini

orcid.org/0000-0001-9137-0805

Specialty section: This article was submitted to

Cancer Genetics,

a section of the journal

Frontiers in Oncology

Received: 09 December 2021 Accepted: 01 February 2022

Published: 08 March 2022

Citation:

Mazziotta C, Lanzillotti C, Gafà $R$

Touzé A, Durand M-A, Martini F and

Rotondo JC (2022) The Role of Histone

Post-Translational Modifications

in Merkel Cell Carcinoma.

Front. Oncol. 12:832047.

doi: 10.3389/fonc.2022.832047
Merkel Cell Carcinoma (MCC) is a rare but highly aggressive form of non-melanoma skin cancer whose 5 -year survival rate is 63\%. Merkel cell polyomavirus (MCPyV), a small DNA tumor virus, is the etiological agent of MCC. Although representing a small proportion of MCC cases, MCPyV-negative MCCs have also been identified. The role of epigenetic mechanisms, including histone post-translational modifications (PTMs) in MCC, have been only partially determined. This review aims to describe the most recent progress on PTMs and their regulative factors in the context of MCC onset/development, providing an overview of current findings on both MCC subtypes. An outline of current knowledge on the potential employment of PTMs and related factors as diagnostic and prognostic markers, as well as novel treatment strategies targeting the reversibility of PTMs for MCC therapy is provided. Recent research shows that PTMs are emerging as important epigenetic players involved in MCC onset/development, and therefore may show a potential clinical significance. Deeper and integrated knowledge of currently known PTM dysregulations is of paramount importance in order to understand the molecular basis of MCC and improve the diagnosis, prognosis, and therapeutic options for this deadly tumor.

Keywords: Merkel cell carcinoma, histone post-translational modifications, epigenetics, Merkel cell polyomavirus, acetylation, methylation, phosphorylation, histone deacetylase inhibitors

\section{INTRODUCTION}

Merkel cell carcinoma (MCC) is a rare, but aggressive non-melanoma skin cancer (1-3). Although similar presentation and prognosis, two different MCC aetiologies have been identified. The first, which accounts for the highest proportion (4-8), $80 \%$ of cases, is caused by a DNA tumor virus belonging to the polyomaviridae family, i.e., Merkel cell polyomavirus (MCPyV) $(2,9)$. The expression of the two viral oncoproteins truncated large T antigen (tLT) and small T antigen (sT), alongside the integration of the MCPyV DNA into the host genome, are the main events for MCPyV-positive MCC (MCCP) onset (9-12). In MCCP cells, LT expression leads to cell proliferation maintenance (13), while sT is required for cell transformation and survival (14). 
The second MCC form MCPyV-negative (MCCN), is caused by high levels of UV-induced tumorigenic point mutations (10, 15, 16). Despite MCCN tumor having a high mutational burden, MCCP harbours a 100-fold lower mutational load (17). According to the Surveillance, Epidemiology, and End Results (SEER) Program, the MCC 5-year survival rate is 76, 53 and 19\% for localized, regional and distant disease, respectively, with an overall combined rate of $63 \%(18-21)$. MCC global incidence ranges 0.1-1.6 cases/100,000 individuals (22). UV light exposure in fair-skinned people, possibly due to occupational sunlight exposure (23), anti-viral/-tumor immunological decline $(6,24,25)$, and old age are considered as MCC risk factors (26). MCC onset risk increases in patients under iatrogenic immunosuppression (9, 27-29). At primary diagnosis, $\sim 30 \%$ of MCC patients present adjacent metastasis and/or lymph node metastases (26), while current therapies are poor. The most effective MCC therapy is cisplatin and etoposide cytotoxic chemotherapy. However, this therapeutic approach is limited by mean progression-free survival being estimated at $\sim 3$ months (30). Moreover, some patients are not responders and/or develop therapy resistance. Surgery and radiation therapies are adopted for local and nodal $\operatorname{MCC}(31,32)$, while systemic therapy is preferred for extensive, metastatic, and recurrent tumor. Even when early diagnosed, patients may not be eligible for surgery/radiotherapy due to other comorbidities. The use of Programmed cell death protein 1 (PD-1) and Programmed death-ligand 1 (PD-L1) inhibitors seems to be an effective therapeutic approach (33-36). Novel therapies are also under evaluation $(31,36-38)$.

The role of histone post-translational modifications (PTMs) in MCC has been remarked upon (2). PTMs, DNA methylation and microRNAs (miRNAs), are fundamental epigenetic mechanisms for controlling gene expression (39-42). These mechanisms collectively determine the accessibility of gene promoters to RNA polymerase II and transcription factors. Histone octamer core complex is composed of two copies each histone protein $\mathrm{H} 2 \mathrm{~A}, \mathrm{H} 2 \mathrm{~B}, \mathrm{H} 3$, and $\mathrm{H} 4$ and is surrounded by $147 \mathrm{bp}$ of DNA to form a nucleosome, the main structural chromatin unit (43). PTMs mostly occur on histone N-Terminal regions (histone tails) protruding from the histone core. These modifications regulate the expression of genes by chromatin remodelling. The combination of single/multiple PTMs and their regulatory role on gene expression are referred to as histone code (44). These processes typically occur in concert with DNA methylation (45-47). The main PTMs are acetylation, methylation, and phosphorylation. Less well-understood PTMs include glycosylation, ubiquitylation, sumoylation, carbonylation and ribosylation (48). The combination of different PTMs can modulate gene expression. Impairment of both PTMs and modifying enzymes has been associated with various diseases, including cancer $(2,49)$. However, despite large number of PTMs and modifying enzymes being identified, a functional understanding of most is still yet to be gained.

Growing evidence indicates that PTM dysregulation play a role in MCC $(2,50,51)$. Studies aimed at epigenetically characterizing MCC have reported data on acetylation, methylation, and phosphorylation, alongside histone modifying enzymes (2). However, the relationship between these dysregulations and MCC onset, progression and metastasis have only been covered partially, while the clinical application of most remains to be determined. Moreover, how MCPyV oncoproteins are capable of dysregulating PTMs in MCCP onset is unclear. Indeed, unlike other DNA tumor viruses (5256) whose oncogenic activity has been linked (57, 58), and demonstrated as functionally dysregulating a variety of PTMs $(59,60)$, little information has yet been reported for MCPyV. Notably, PTM dysregulation offers both diagnostic and prognostic potential in the clinic and represents a therapeutic target in a large variety of tumors (57).

This review is addressed at collecting and summarizing the state of the art on PTMs and regulative factors whose dysregulation has been assumed to play a role in MCC. A description of current knowledge on the potential usage of PTMs and regulative factors as diagnostic and prognostic tools, as well as targets for MCC therapy is also provided.

\section{HISTONE POST-TRANSLATIONAL MODIFICATIONS AND MERKEL CELL CARCINOMA}

\section{Histone Acetylation}

Histone acetylation occurs on lysine residues and leads to chromatin relaxation by creating repulsive forces with the negatively charged DNA. This process makes the DNA accessible to the transcription factors, ultimately leading to gene expression (61-63). Histone deacetylation generally induces chromatin condensation while being linked to gene silencing (64). Histone acetylation is mediated by Histone Acetyltransferases (HATs), while Histone Deacetylases (HDACs) catalyze deacetylation reactions (65).

Histone acetylation dysregulation is involved in MCC host immune-surveillance escape. As other tumors (25, 66-68), MCC present strong immuno-selective pressures and, thus, arises and progress when developing efficient immune escape mechanisms. One strategy provides the improper recognition by T cells owing to the downregulation of major histocompatibility complex (MHC) class-I on tumor cell surfaces. Indeed, MHC class-I encodes for surface receptors which are essential for the adaptive immune system $(66,69,70)$. Ritter and colleagues reported on the loss of $\mathrm{MHC}$ class I chain-related protein (MIC) A and B expression in MCCP cells (71). MICs are polymorphic proteins whose expression is induced upon cell transformation and act as kill me signals for natural killer cells, which are therefore activated against tumor cells during the innate immune response. This loss has been afterwards reported as a consequence of $\mathrm{H} 3 \mathrm{~K} 9$ deacetylation nearby the MIC promoter (71). MIC expression can also be epigenetically restored by pharmacological treatment with the HDAC inhibitor (iHDAC) Vorinostat (Figure 1) (71). Additional cell surface receptors encoded by MHC locus, i.e., HLA class-I complex, have been reported as down-regulated MCC tissues 

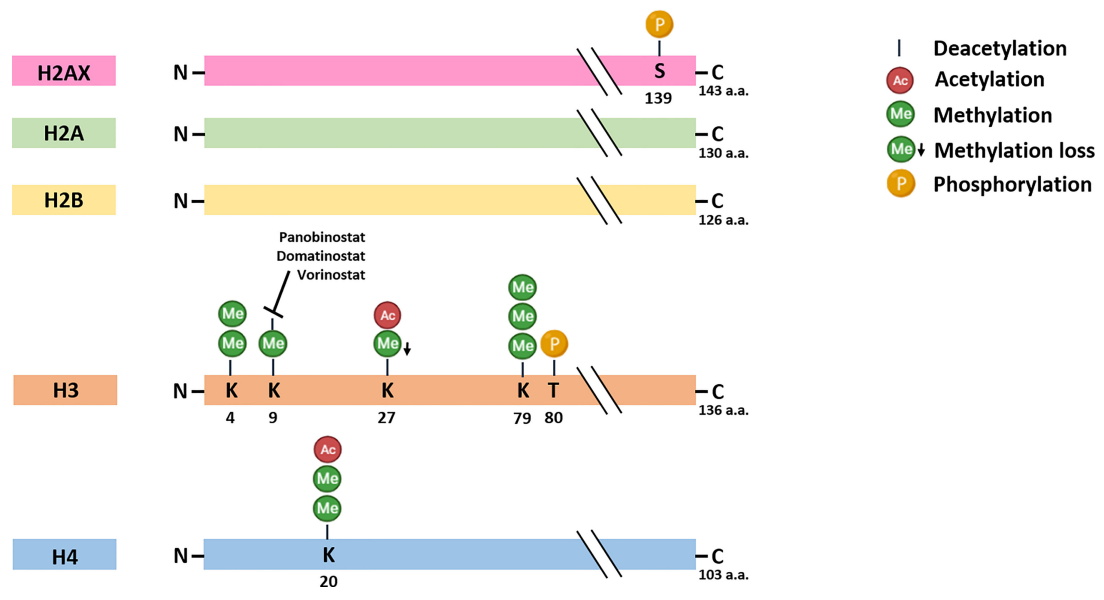

FIGURE 1 | Histone post-translational modifications in Merkel cell carcinoma. The specific modifications and amino acids (a.a.) residues are reported. Histone deacetylase inhibitors Panobinostat, Domatinostat and Vorinostat has been found to restore histone acetylation in vitro in MCC cell lines, thereby promoting gene expression. S, Serine; K, Lysine; T, Threonine.

with unknown MCPyV-positivity and in MCCP cell lines (69). This down-regulation has been related to the impaired expression of key components of antigen processing machinery (APM), including low-molecular-weight protein (LMP) 2 and LMP7, as well as a transporter associated with Antigen Processing 1 and 2. In vitro/in vivo data also indicate that HLA class-I APM down-regulation is attributable to a dysregulated $\mathrm{H} 3 \mathrm{~K} 9$ deacetylation in proximity to APM gene promoters, whilst Vorinostat has been reported as capable of restoring their expression (69). The epigenetic re-expression of HLA class-I on the surfaces of MCC cells has also been demonstrated with Domatinostat, an orally available iHDAC (Figure 1) (72). Following pharmacological treatments, RNA sequencing and functional experiments indicated a distinct gene expression signature for antigen processing and presentation, cell-cycle arrest and apoptosis. Therefore, the re-expression of HLA class-I by Domatinostat might favour MCC cell identification and eradication by the anti-tumor immune response (72).

Inhibitory receptors expression on tumor-targeted immune cells and tumor cells surfaces can be considered as another MCC immune escape mechanism. During cell transformation, the interaction between PD-1 and PD-L1 expressed on the surface of activated $\mathrm{T}$ cells and tumor cells, respectively, reduces $\mathrm{T}$-cell function and prevents the immune system from acting against tumor cells (73). Although PD-1/PD-L1 blockade therapy is promising for cancer treatment (74), a fraction of patients are either non-responders or develop resistance $(75,76)$. To circumvent these negative responses, therapies combining PD1/PD-L1 blockers and iHDACs have been developed for MCC. A Phase II clinical trial (NCT04393753) is currently ongoing to investigate the efficacy/safety of the anti-PD-L1 antibody avelumab in combination with domatinostat in MCC patients. Furthermore, the iHDAC Panobinostat has been administered to a small group of PD-1/PD-L1 non-responder metastatic MCC patients (77). The pharmacological treatment of two patients with Panobinostat was reported as inducing a restored HLA class-I expression and an increase in $\mathrm{CD}^{+} \mathrm{T}$-cell infiltration in tumor tissues. These data suggest that iHDACs might be helpful in overcoming HLA class-I expression loss in PD-1/PD-L1 nonresponder patients (77). In summary, histone acetylation dysregulation in chief immune system players represents a key mechanism whereby MCC can escape the anti-tumor response, while expression restoration in immune regulatory complexes by iHDACs epigenetic priming might be a helpful therapeutic approach based on boosting adaptive immune responses (38).

Histone acetylation impairment in MCC encompasses the dysregulation of proto-oncogene $c-M y c$ (50). In MCC tissues/ cells with unknown MCPyV positivity and in MCCP cell lines, c-Myc overexpression has been linked to acetylated lysine 27 enrichment at histone $\mathrm{H} 3$ ( $\mathrm{H} 3 \mathrm{~K} 27 \mathrm{Ac}$ ) in an enhancer proximal to the $c-M y c$ promoter. At the same time, high occupancy of Bromodomain protein 4 (BRD4), a gene expression regulator which binds to $\mathrm{H} 3 \mathrm{~K} 27 \mathrm{Ac}$, has also been reported. Also, in vitro treatment with bromodomain and extra-terminal (BET) inhibitors (iBETs), a class of drugs that reversibly bind to BET family proteins, comprising BRD4, depleted BRD4 occupancy at the $c-M y c$ enhancer and induced $c-M y c$ downregulation (50). This evidence underlines not only that both $\mathrm{H} 3 \mathrm{~K} 27 \mathrm{Ac}$ and BRDs play a role in MCC, but also that iHDAC and iBET combination therapy should be considered as a novel therapeutic approach.

\section{Histone Methylation}

Histone methylation provides the addition of a methyl group on lysine and arginine residues, which can undergo mono-/di-/ trimethylation, and mono-/dimethylation, respectively. Enzymes mediating histone methylation and demethylation reactions are histone methyltransferases (HMTs) and demethylases (HDMs), respectively (78). Histone methylation can be associated with either transcriptional repression or 
activation (79, 80). Important HMT/HDM enzymes are: (i) Enhancer of zeste homolog 2 (EZH2) which is the catalytic subunit of the Polycomb Repressive Complex 2 (PRC2); the complex methylates lysine 27 in histone H3 (H3K27) (81), a repressive mark on tumor suppressor gene promoters during tumorigenesis $(82,83)$; (ii) Lysine-specific demethylase 1 (LSD1) which removes the mono-/di- methylation marks in lysine 4 and 9 of histone $\mathrm{H} 3(\mathrm{H} 3 \mathrm{~K} 4 / 9)(84,85)$. H3K9 tri-methylation is almost exclusively localized in pericentric heterochromatin, repetitive elements and non-coding portions of the genome (86), while H3K27 tri-methylation is mainly associated with gene silencing and can be found in genes rich areas $(87,88)$. Methylated H3K4 has been found in transcriptionally active euchromatic regions (89).

Significant attention has been paid to histone methylation and particularly to LSD1 $(17,90)$, with the aim of developing novel MCC therapies (Figure 1) $(17,91,92)$. During MCCP onset, sT can interact with several factors, such as MYCL and MAX. Both factors are recruited to the EP400 subunit (or p400) of the histone acetyltransferase complex by sT (90). Improper complex activation leads to LSD1 overexpression, thereby favouring MCC growth in vitro/in vivo (91). Consistently, LSD1 inhibition in vitro can induce cell cycle arrest and apoptosis in MCCP cells, while activating a gene expression signature which resembles normal Merkel cells; tumor growth inhibition has also been shown in vivo (17). LSD1 inhibition could therefore be considered as an additional MCC therapeutic option (17, 91-93).

The role played by PRC2 and its functional enzymatic component EZH2 in MCC progression and metastasis has been remarked upon. Increased EZH2 expression has been reported as associated with both MCC progression and poor prognosis (81). Immunohistochemistry (IHC) experiments conducted on MCCP and MCCN tissues, including primary tumors, as well as lymph node, in-transit and distant metastases, reported about half specimens as exhibiting strong/moderate EZH2 expression. Weak EZH2 expression in the primary tumor, but not nodal metastases, has been correlated with improved prognosis. High EZH2 expression levels have also been reported in a set of MCC tissues, with no differences according to MCPyV presence (94). Although H3K27me3 has not been studied, these papers underlined the prognostic value of EZH2 in MCC, thus suggesting that this HMT might be a potential target for MCC treatment.

Additional studies have examined $\mathrm{H} 3 \mathrm{~K} 27 \mathrm{me} 3$ in different primary/metastatic MCC tissue specimens, such as: (i) MCCP and MCCN tumors with pure histological features, including primary and metastatic lesions, as well as a small number of combined squamous and neuroendocrine carcinomas (51); (ii) different tumor types, including MCC (95); (iii) MCC tissues stratified according to $\mathrm{MCPyV}$ status and morphological type (49). The first study described reduced H3K27me3 expression in MCCPs and in MCCs with pure histologic features (51). The second reported $\mathrm{H} 3 \mathrm{~K} 27 \mathrm{me} 3$ loss in $90 \%$ of MCCs with unknown MCPyV positivity, while all MCCs were H3K27me2-positive (95). The third reported low H3K27me3 levels in MCCN compared to MCCP tumors, and in particular in MCCNs combined with squamous cell carcinoma than in MCCP/N pure tumors or pure histologic MCCs (regardless of MCPyV status). Following prospective analyses indicated a lack of correlation between low $\mathrm{H} 3 \mathrm{~K} 27 \mathrm{me} 3$ and MCC patient outcome, thus excluding a prognostic role for this epigenetic mark (49). Considering these data, the loss of H3K27me2/me3 marks in MCC might be attributable to an impairment in PRC2 activity (96). However, neither PRC2 expression nor activity has been evaluated in these studies. H3K27me2/me3 modifications might potentially be due to PRC2 levels/activity changes. However, a link between PRC2 and H3K27me2/me3 upon MCC has not been determined. In this context, whether PRC2 and its epigenetic marks play a role in MCC onset is yet to be verified with further studies.

The important role of histone methyltransferase PRDM8 in MCCN development has recently been highlighted (97). High PRDM8 mRNA levels have been reported in MCCN cell lines, while PRDM8 overexpression has been found as linked to an increase in $\mathrm{H} 3$ lysine 9 methylation (H3K9me) global levels in MCCN specimens. Notably, the same study also identified $m i R$ $20 a-5 p$ as an upstream PRDM8 regulator, pointing to its involvement in MCC tumorigenesis as a tumor suppressor miRNA. Taken together, these findings provide insight into the role of PRDM8 and histone methylation in MCC (97).

\section{Histone Phosphorylation}

Histone phosphorylation provides the addition of phosphate groups to serine, tyrosine and/or threonine residues (98-100). Phosphatases and kinases are the two enzyme classes known to remove and include the phosphate groups, respectively $(101,102)$. Although being somewhat less well-understood than acetylation and methylation, phosphorylation seems to be linked to positive gene regulation, as leading to chromatin relaxation $(101,102)$.

The involvement of histone phosphorylation in MCC has been investigated in studies focused in both histone methylation and phosphorylation marks. H3 lysine 79 trimethylation/H3 threonine 80 phosphorylation (H3K79me3T80ph, or H3KT) and $\mathrm{H} 3$ phosphorylation ( $\mathrm{PHH} 3)$ marks, which are both expressed during G2/M phase progression, have been assessed as prognostic markers for MCC in relation to mitotic figures and $\mathrm{G} 2+$ tumor nuclei. The latter are both proliferation indicators. Despite the limited number of MCC patients enrolled in the study, H3KT/PHH3 marks, evaluated by IHC in MCC tissues with unknown MCPyV positivity, had prognostic significance in stratifying patient risk in relation to proliferative rates (103). The role of histone methylation and phosphorylation in MCCP during MCPyV sT-induced DNA damage response (DDR) pathway activation has also been reported (104). MCPyV sT overexpression has been described as functionally inducing (i) H2AX phosphorylation via ataxia telangiectasia mutant (ATM) activation, which is a crucial upstream kinase for $\mathrm{H} 2 \mathrm{AX}$ phosphorylation; (ii) dimethylation of $\mathrm{H} 3$ lysine 4 (H3K4me2) and $\mathrm{H} 4$ lysine 20 (H4K20me2). Moreover, phosphorylation of other DDR/ATM downstream proteins has also been described. These findings cumulatively suggest the contribution of histone 
methylation and phosphorylation in MCPyV sT-induced DDR pathway activation upon MCCP onset (104).

\section{HISTONE VARIANTS AND MERKEL CELL CARCINOMA}

Mass spectrometry analyses conducted on MCCP cell lines compared to a control epithelial cell line reported a total of 5 different histone families with 15 different subfamily members, including H2A type 1-H as being differentially expressed (105). Although these histones have not been investigated epigenetically, the study highlighted the role of histone variants in MCCP. Further studies might extend these proteome data towards an epigenetic point of view.

\section{DISCUSSION AND FUTURE PERSPECTIVES}

This review summarizes and provides insights into PTMs and related factors being assessed as linked to MCC (Figure 1). While emerging evidence indicates that PTM dysregulations are involved in MCC, the clinical application of most has only been limitingly demonstrated. The impairment of histone acetylation $(50,69,71)$, methylation $(49,51,95)$ and phosphorylation marks $(103,104)$ as well as histone modifying enzymes, including PCR2/EZH2 $(81,94), \operatorname{LSD} 1(17,90,91)$ and PRDM8 (97), have been reported as playing a role in MCC. From a therapeutic point of view, promising data have been obtained with iHDAC inhibitors, such as Vorinostat, Domatinostat and Panobinostat $(17,69,71,72,77)$, as well as with LSD1 inhibitors (17). Moreover, studies conducted with Vorinostat and LSD1 inhibitors have been conducted both in vitro with MCC cells, and in vivo with animal models, thus underling the reliability of these antitumor compounds $(17,69,91)$. The clinical application of iHDACs has also been demonstrated with MCC patients under combination therapy with PD-1/PD-L1 inhibitors in one study and in one phase II clinical trial (NCT04393753) (77). Contrariwise, a few studies questioning PTMs as MCC diagnostic/prognostic markers, comprising histone methylation $(49,51,95)$ and simultaneous methylation and phosphorylation (103), have been reported. Further studies should be performed to identify novel PTMs as MCC diagnostic/prognostic markers.

As hypothesized in the abovementioned studies, the dysregulation of epigenetic mechanisms plays a role in MCC to

\section{REFERENCES}

1. Jin HT, Park SJ, Choi EK, Kim YS. The Frequency of Merkel Cell Polyomavirus in Whole Blood From Immunocompetent and Immunosuppressed Patients With Kidney Disease and Healthy Donors. Microb Pathog (2019) 131:75-80. doi: 10.1016/j.micpath.2019.03.020

2. Rotondo JC, Mazziotta C, Lanzillotti C, Tognon M, Martini F. Epigenetic Dysregulations in Merkel Cell Polyomavirus-Driven Merkel Cell Carcinoma. Int J Mol Sci (2021) 22:11464. doi: 10.3390/ ijms222111464 some extent and therefore represent potential clinical significance. The identification of novel PTMs may improve early MCC diagnosis and therapy monitoring. MCC onset, progression and metastasis is often rapid (32) and early tumor identification, as well as expeditious diagnostic workup and therapy initiation are crucial. Thus, research for novel PTMs to be employed in the clinic should be a priority (106). Since MCC is considered an aggressive and deadly tumor, there is an urgent need to identify novel effective therapies for its management. As the malignant behaviour of MCC cells can be reverted with iHDACs $(17,69,71,72,77)$, combination multidrug therapies with hypomethylating agents should be considered $(45,107,108)$, as has successfully been demonstrated in treating other tumors (109-111). We therefore recommend further rigorous preclinical/clinical studies in this direction (112).

In conclusion, while promising data have been obtained for PTMs and modifying enzymes, the clinical application of most is still to be verified. Further studies are needed for identifying novel PTMs that could be employed as clinical tools. Gaining a deeper understanding of PTM dysregulations is of paramount importance for understanding the molecular basis of MCC and improving the diagnosis, prognosis, and therapeutic options for this tumor.

\section{AUTHOR CONTRIBUTIONS}

CM wrote the first draft of the manuscript. M-AD and RG selected the literature and revised the manuscript draft. CL designed the figures. JCR, AT, and FM organized and supervised the work, and corrected the manuscript draft. CM and JCR wrote the final version of the manuscript. All authors contributed to the article and approved the submitted version.

\section{FUNDING}

This work was supported, in part, by grants MFAG 21956 (to JCR), from the Associazione Italiana per la Ricerca sul Cancro (AIRC), Milan, Italy, and University of Ferrara, FAR grants 2021 (to Fernanda Martini). CM is supported by a AIRC fellowship for Italy (ID: 26829).

\section{ACKNOWLEDGMENTS}

We thank Professor Georgia Emma Gili for revising the English text of the manuscript.

3. Toker C. Trabecular Carcinoma of the Skin. Arch Dermatol (1972) 105:10710. doi: 10.1001/ARCHDERM.1972.01620040075020

4. Feng $H$, Shuda M, Chang Y, Moore PS. Clonal Integration of a Polyomavirus in Human Merkel Cell Carcinoma. Science (80- ) (2008) 319:1096-100. doi: 10.1126/science. 1152586

5. Atkinson AL, Atwood WJ. Fifty Years of JC Polyomavirus: A Brief Overview and Remaining Questions. Viruses (2020) 12(9):969. doi: 10.3390/ v12090969

6. Ferreira DA, Tayyar Y, Idris A, McMillan NAJ. A “Hit-and-Run” Affair - A Possible Link for Cancer Progression in Virally Driven Cancers. Biochim 
Biophys Acta - Rev Cancer (2021) 1875:188476. doi: 10.1016/j.bbcan. 2020.188476

7. Kamminga S, van der Meijden E, de Brouwer C, Feltkamp M, Zaaijer H. Prevalence of DNA of Fourteen Human Polyomaviruses Determined in Blood Donors. Transfusion (2019) 59:3689-97. doi: 10.1111/trf.15557

8. Del Valle L, Piña-Oviedo S. Human Polyomavirus JCPyV and Its Role in Progressive Multifocal Leukoencephalopathy and Oncogenesis. Front Oncol (2019) 9:711. doi: 10.3389/fonc.2019.00711

9. Rotondo JC, Bononi I, Puozzo A, Govoni M, Foschi V, Lanza G, et al. Merkel Cell Carcinomas Arising in Autoimmune Disease Affected Patients Treated With Biologic Drugs Including Anti-TNF. Clin Cancer Res (2017) 23:392934. doi: 10.1158/1078-0432.CCR-16-2899

10. Pietropaolo V, Prezioso C, Moens U. Merkel Cell Polyomavirus and Merkel Cell Carcinoma. Cancers (Basel) (2020) 12:1774. doi: 10.3390/ cancers 12071774

11. Del Marmol V, Lebbé C. New Perspectives in Merkel Cell Carcinoma. Curr Opin Oncol (2019) 31:72-83. doi: 10.1097/CCO.0000000000000508

12. Martel-Jantin C, Filippone C, Cassar O, Peter M, Tomasic G, Vielh P, et al. Genetic Variability and Integration of Merkel Cell Polyomavirus in Merkel Cell Carcinoma. Virology (2012) 426:134-42. doi: 10.1016/J.VIROL. 2012.01.018

13. Hesbacher S, Pfitzer L, Wiedorfer K, Angermeyer S, Borst A, Haferkamp S, et al. RB1 is the Crucial Target of the Merkel Cell Polyomavirus Large T Antigen in Merkel Cell Carcinoma Cells. Oncotarget (2016) 7:32956-68. doi: 10.18632 /oncotarget. 8793

14. Angermeyer S, Hesbacher S, Becker JC, Schrama D, Houben R. Merkel Cell Polyomavirus-Positive Merkel Cell Carcinoma Cells do Not Require Expression of the Viral Small T Antigen. J Invest Dermatol (2013) 133:2059-64. doi: 10.1038/jid.2013.82

15. Starrett GJ, Thakuria M, Chen T, Marcelus C, Cheng J, Nomburg J, et al. Clinical and Molecular Characterization of Virus-Positive and VirusNegative Merkel Cell Carcinoma. Genome Med (2020) 12:30. doi: 10.1186/ s13073-020-00727-4

16. Csoboz B, Rasheed K, Sveinbjørnsson B, Moens U. Merkel Cell Polyomavirus and non-Merkel Cell Carcinomas: Guilty or Circumstantial Evidence? APMIS (2020) 128(2):104-120. doi: 10.1111/apm.13019

17. Leiendecker L, Jung PS, Krecioch I, Neumann T, Schleiffer A, Mechtler K, et al. LSD 1 Inhibition Induces Differentiation and Cell Death in Merkel Cell Carcinoma. EMBO Mol Med (2020) 12:e12525. doi: 10.15252/emmm. 202012525

18. Lewis CW, Qazi J, Hippe DS, Lachance K, Thomas H, Cook MM, et al. Patterns of Distant Metastases in 215 Merkel Cell Carcinoma Patients: Implications for Prognosis and Surveillance. Cancer Med (2020) 9:1374-82. doi: $10.1002 / \mathrm{cam} 4.2781$

19. Zwijnenburg EM, Lubeek SFK, Werner JEM, Amir AL, Weijs WLJ, Takes RP, et al. Merkel Cell Carcinoma: New Trends. Cancers (Basel) (2021) 13 (7):1614. doi: 10.3390/cancers13071614

20. Murakami I, Wada N, Nakashima J, Iguchi M, Toi M, Hashida Y, et al. Merkel Cell Polyomavirus and Langerhans Cell Neoplasm. Cell Commun Signal (2018) 16:49. doi: 10.1186/s12964-018-0261-y

21. SEER. Surveillance, Epidemiology, and End Results Program (2022). SEER. Available at: https://seer.cancer.gov/ (Accessed January 27, 2022).

22. Xue Y, Thakuria M. Merkel Cell Carcinoma Review. Hematol Oncol Clin North Am (2019) 33:39-52. doi: 10.1016/j.hoc.2018.08.002

23. Stang A, Becker J, Nghiem P, Ferlay J. The Association Between Geographic Location and Incidence of Merkel Cell Carcinoma in Comparison to Melanoma: An International Assessment. Eur J Cancer (2018) 94:47-60. doi: 10.1016/J.EJCA.2018.02.003

24. Prezioso C, Obregon F, Ambroselli D, Petrolo S, Checconi P, Rodio DM, et al. Merkel Cell Polyomavirus (MCPyV) in the Context of Immunosuppression: Genetic Analysis of Noncoding Control Region (NCCR) Variability Among a HIV-1-Positive Population. Viruses (2020) 12(5):507. doi: 10.3390/v12050507

25. Krump NA, Liu W, You J. Mechanisms of Persistence by Small DNA Tumor Viruses. Curr Opin Virol (2018) 32:71-9. doi: 10.1016/j.coviro.2018.09.002

26. Becker JC, Stang A, Decaprio JA, Cerroni L, Lebbé C, Veness M, et al. Merkel Cell Carcinoma. Nat Rev Dis Prim (2017) 3:17077. doi: 10.1038/ NRDP.2017.77
27. Clarke CA, Robbins HA, Tatalovich Z, Lynch CF, Pawlish KS, Finch JL, et al. Risk of Merkel Cell Carcinoma After Solid Organ Transplantation. J Natl Cancer Inst (2015) 107(2):dju382. doi: 10.1093/jnci/dju382

28. Mazziotta C, Pellielo G, Tognon M, Martini F, Rotondo JC, Martini F, et al. Significantly Low Levels of IgG Antibodies Against Oncogenic Merkel Cell Polyomavirus in Sera From Females Affected by Spontaneous Abortion. Front Microbiol (2021) 12:789991. doi: 10.3389/FMICB.2021.789991

29. Jacques C, Floris I, Lejeune B. Ultra-Low Dose Cytokines in Rheumatoid Arthritis, Three Birds With One Stone as the Rationale of the $2 \mathrm{LARTH}^{\circledR}$ Micro-Immunotherapy Treatment. Int J Mol Sci (2021) 22:6717. doi: 10.3390/IJMS22136717

30. Iyer JG, Blom A, Doumani R, Lewis C, Tarabadkar ES, Anderson A, et al. Response Rates and Durability of Chemotherapy Among 62 Patients With Metastatic Merkel Cell Carcinoma. Cancer Med (2016) 5:2294. doi: 10.1002/ CAM4.815

31. Villani A, Fabbrocini G, Costa C, Carmela Annunziata M, Scalvenzi M. Merkel Cell Carcinoma: Therapeutic Update and Emerging Therapies. Dermatol Ther (Heidelb) (2019) 9:209-22. doi: 10.1007/S13555-019-0288-Z

32. Dubois M, Abi Rached H, Escande A, Dezoteux F, Darloy F, Jouin A, et al. Outcome of Early Stage Merkel Carcinoma Treated by Exclusive Radiation: A Study of 53 Patients. Radiat Oncol (2021) 16:90. doi: 10.1186/s13014-02101815-4

33. Colunga A, Pulliam T, Nghiem P. Merkel Cell Carcinoma in the Age of Immunotherapy: Facts and Hopes. Clin Cancer Res (2018) 24:2035-43. doi: 10.1158/1078-0432.CCR-17-0439

34. Nghiem PT, Bhatia S, Lipson EJ, Kudchadkar RR, Miller NJ, Annamalai L, et al. PD-1 Blockade With Pembrolizumab in Advanced Merkel-Cell Carcinoma. N Engl J Med (2016) 374:2542-52. doi: 10.1056/NEJMOA1603702/ SUPPL_FILE/NEJMOA1603702_DISCLOSURES.PDF

35. Nghiem P, Bhatia S, Lipson EJ, Sharfman WH, Kudchadkar RR, Brohl AS, et al. Durable Tumor Regression and Overall Survival in Patients With Advanced Merkel Cell Carcinoma Receiving Pembrolizumab as First-Line Therapy. J Clin Oncol (2019) 37:693-702. doi: 10.1200/JCO.18.01896

36. Samimi M. Immune Checkpoint Inhibitors and Beyond: An Overview of Immune-Based Therapies in Merkel Cell Carcinoma. Am J Clin Dermatol (2019) 20:391-407. doi: 10.1007/s40257-019-00427-9

37. Nghiem P, Bhatia S, Lipson EJ, Sharfman WH, Kudchadkar RR, Brohl AS, et al. Three-Year Survival, Correlates and Salvage Therapies in Patients Receiving First-Line Pembrolizumab for Advanced Merkel Cell Carcinoma. J Immunother Cancer (2021) 9:e002478. doi: 10.1136/JITC-2021-002478

38. Bobrowicz M, Zagozdzon R, Domagala J, Vasconcelos-Berg R, Guenova E, Winiarska M. Monoclonal Antibodies in Dermatooncology-State of the Art and Future Perspectives. Cancers (Basel) (2019) 11(10):1420. doi: 10.3390/ cancers 11101420

39. Lanzillotti C, De Mattei M, Mazziotta C, Taraballi F, Rotondo JC, Tognon $\mathrm{M}$, et al. Long Non-Coding RNAs and MicroRNAs Interplay in Osteogenic Differentiation of Mesenchymal Stem Cells. Front Cell Dev Biol (2021) 9:646032. doi: 10.3389/fcell.2021.646032

40. Rotondo JC, Lanzillotti C, Mazziotta C, Tognon M, Martini F. Epigenetics of Male Infertility: The Role of DNA Methylation. Front Cell Dev Biol (2021) 9:689624. doi: 10.3389/fcell.2021.689624

41. Rotondo JC, Aquila G, Oton-Gonzalez L, Selvatici R, Rizzo P, De Mattei M, et al. Methylation of SERPINA1 Gene Promoter may Predict Chronic Obstructive Pulmonary Disease in Patients Affected by Acute Coronary Syndrome. Clin Epigenet (2021) 13:79. doi: 10.1186/s13148-021-01066-w

42. Rotondo JC, Oton-Gonzalez L, Selvatici R, Rizzo P, Pavasini R, Campo GC, et al. SERPINA1 Gene Promoter is Differentially Methylated in Peripheral Blood Mononuclear Cells of Pregnant Women. Front Cell Dev Biol (2020) 8:550543. doi: $10.3389 /$ fcell.2020.550543

43. Luger K, Mäder AW, Richmond RK, Sargent DF, Richmond TJ. Crystal Structure of the Nucleosome Core Particle at $2.8 \AA$ Resolution. Nature (1997) 389:251-60. doi: 10.1038/38444

44. Chen P, Guo Z, Chen C, Tian S, Bai X, Zhai G, et al. Identification of Dual Histone Modification-Binding Protein Interaction by Combining Mass Spectrometry and Isothermal Titration Calorimetric Analysis. J Adv Res (2020) 22:35-46. doi: 10.1016/j.jare.2019.11.003

45. Stomper J, Rotondo JC, Greve G, Lübbert M. Hypomethylating Agents (HMA) for the Treatment of Acute Myeloid Leukemia and Myelodysplastic 
Syndromes: Mechanisms of Resistance and Novel HMA-Based Therapies. Leukemia (2021) 35:1873-89. doi: 10.1038/s41375-021-01218-0

46. Gonçalves AC, Alves R, Baldeiras I, Marques B, Oliveiros B, Pereira A, et al. DNA Methylation Is Correlated With Oxidative Stress in Myelodysplastic Syndrome-Relevance as Complementary Prognostic Biomarkers. Cancers (2021) 13:3138. doi: 10.3390/CANCERS13133138. 2021, Vol 13, Page 3138.

47. Rotondo JC, Selvatici R, Di Domenico M, Marci R, Vesce F, Tognon M, et al. Methylation Loss at H19 Imprinted Gene Correlates With Methylenetetrahydrofolate Reductase Gene Promoter Hypermethylation in Semen Samples From Infertile Males. Epigenetics (2013) 8:990-7. doi: 10.4161/epi.25798

48. Sharma A, Sharma KL, Bansal C, Kumar A. Updates on "Cancer Genomics and Epigenomics". World J Clin Oncol (2020) 11:890-7. doi: 10.5306/ wjco.v11.i11.890

49. Matsushita M, Iwasaki T, Wardhani LO, Kuwamoto S, Nonaka D, Nagata K, et al. Decreased H3K27me3 Expression is Associated With Merkel Cell Polyomavirus-Negative Merkel Cell Carcinoma, Especially Combined With Cutaneous Squamous Cell Carcinoma. Anticancer Res (2019) 39:5573-9. doi: 10.21873/anticanres.13751

50. Sengupta D, Kannan A, Kern M, Moreno MA, Vural E, Stack B, et al. Disruption of BRD4 at H3K27Ac-Enriched Enhancer Region Correlates With Decreased C-Myc Expression in Merkel Cell Carcinoma. Epigenetics (2015) 10:460-6. doi: 10.1080/15592294.2015.1034416

51. Busam KJ, Pulitzer MP, Coit DC, Arcila M, Leng D, Jungbluth AA, et al. Reduced H3K27me3 Expression in Merkel Cell Polyoma Virus-Positive Tumors. Mod Pathol (2017) 30:877-83. doi: 10.1038/modpathol.2017.8

52. Tognon M, Tagliapietra A, Magagnoli F, Mazziotta C, Oton-Gonzalez L, Lanzillotti C, et al. Investigation on Spontaneous Abortion and Human Papillomavirus Infection. Vaccines (2020) 8:473. doi: 10.3390/vaccines 8030473

53. Rotondo JC, Oton-Gonzalez L, Mazziotta C, Lanzillotti C, Iaquinta MR, Tognon M, et al. Simultaneous Detection and Viral DNA Load Quantification of Different Human Papillomavirus Types in Clinical Specimens by the High Analytical Droplet Digital PCR Method. Front Microbiol (2020) 11:591452. doi: 10.3389/fmicb.2020.591452

54. Oton-Gonzalez L, Rotondo JC, Cerritelli L, Malagutti N, Lanzillotti C, Bononi I, et al. Association Between Oncogenic Human Papillomavirus Type 16 and Killian Polyp. Infect Agent Cancer (2021) 16:3. doi: 10.1186/ s13027-020-00342-3

55. Malagutti N, Rotondo JC, Cerritelli L, Melchiorri C, De Mattei M, Selvatici $\mathrm{R}$, et al. High Human Papillomavirus DNA Loads in Inflammatory Middle Ear Diseases. Pathogens (2020) 9:227. doi: 10.3390/pathogens9030224

56. Preti M, Rotondo JC, Holzinger D, Micheletti L, Gallio N, Robitaille A, et al. Role of Human Papillomavirus Infection in the Etiology of Vulvar Cancer in Italian Women. Infect Agent Cancer (2020) 15:e2020. doi: 10.1186/s13027020-00286-8

57. Lourenço de Freitas N, Deberaldini MG, Gomes D, Pavan AR, Sousa Â, Dos Santos JL, et al. Histone Deacetylase Inhibitors as Therapeutic Interventions on Cervical Cancer Induced by Human Papillomavirus. Front Cell Dev Biol (2021) 8:592868. doi: 10.3389/fcell.2020.592868

58. David S, Christine S, Margaret M-D. Epigenetic Alterations in Human Papillomavirus-Associated Cancers. Viruses (2017) 9:248. doi: 10.3390/ v9090248

59. Liu J, Zhao H, Zhang Q, Shi Z, Zhang Y, Zhao L, et al. Human Papillomavirus Type 16 E7 Oncoprotein-Induced Upregulation of LysineSpecific Demethylase 5A Promotes Cervical Cancer Progression by Regulating the microRNA-424-5p/Suppressor of Zeste 12 Pathway. Exp Cell Res (2020) 396(1):112277. doi: 10.1016/j.yexcr.2020.112277

60. Erika L, Jason B, Laimonis L. The Deacetylase Sirtuin 1 Regulates Human Papillomavirus Replication by Modulating Histone Acetylation and Recruitment of DNA Damage Factors NBS1 and Rad51 to Viral Genomes. PLoS Pathog (2015) 1005181:1-21. doi: 10.1371/journal.ppat.1005181

61. McCool KW, Xu X, Singer DB, Murdoch FE, Fritsch MK. The Role of Histone Acetylation in Regulating Early Gene Expression Patterns During Early Embryonic Stem Cell Differentiation. J Biol Chem (2007) 282:6696706. doi: 10.1074/jbc.M609519200

62. Mazziotta C, Rotondo JC, Lanzillotti C, Campione G, Martini F, Tognon M. Cancer Biology and Molecular Genetics of A3 Adenosine Receptor. Oncogene (2021) 41(3):301-8. doi: 10.1038/s41388-021-02090-z
63. Rotondo JC, Giari L, Guerranti C, Tognon M, Castaldelli G, Fano EA, et al. Environmental Doses of Perfluorooctanoic Acid Change the Expression of Genes in Target Tissues of Common Carp. Environ Toxicol Chem (2018) 37:942-8. doi: 10.1002/etc.4029

64. Milon BC, Cheng H, Tselebrovsky MV, Lavrov SA, Nenasheva VV, Mikhaleva EA, et al. Role of Histone Deacetylases in Gene Regulation at Nuclear Lamina. PLoS One (2012) 7(11):e49692. doi: 10.1371/ journal.pone.0049692

65. Pelzel HR, Schlamp CL, Nickells RW. Histone H4 Deacetylation Plays a Critical Role in Early Gene Silencing During Neuronal Apoptosis. BMC Neurosci (2010) 11:62. doi: 10.1186/1471-2202-11-62

66. Paulson KG, Tegeder A, Willmes C, Iyer JG, Afanasiev OK, Schrama D, et al. Downregulation of MHC-I Expression Is Prevalent But Reversible in Merkel Cell Carcinoma. Cancer Immunol Res (2014) 2:1071-9. doi: 10.1158/23266066.CIR-14-0005

67. Davies SI, Muranski P. T Cell Therapies for Human Polyomavirus Diseases. Cytotherapy (2017) 19:1302-16. doi: 10.1016/j.jcyt.2017.08.011

68. White EA, Shanmugasundaram S, You J. Manipulation of the Host Immune Response by Small DNA Tumor Viruses. Cham: Humana Press (2019) 26197. doi: 10.1007/978-3-030-04155-7_13

69. Ritter C, Fan K, Paschen A, Reker Hardrup S, Ferrone S, Nghiem P, et al. Epigenetic Priming Restores the HLA Class-I Antigen Processing Machinery Expression in Merkel Cell Carcinoma. Sci Rep (2017) 7:2290. doi: 10.1038/ s41598-017-02608-0

70. Schadendorf D, Nghiem P, Bhatia S, Hauschild A, Saiag P, Mahnke L, et al. Immune Evasion Mechanisms and Immune Checkpoint Inhibition in Advanced Merkel Cell Carcinoma. Oncoimmunology (2017) 6:e1338237. doi: 10.1080/2162402X.2017.1338237

71. Ritter C, Fan K, Paulson KG, Nghiem P, Schrama D, Becker JC. Reversal of Epigenetic Silencing of MHC Class I Chain-Related Protein A and B Improves Immune Recognition of Merkel Cell Carcinoma. Sci Rep (2016) 23:21678. doi: $10.1038 / \mathrm{srep} 21678$

72. Song L, Bretz AC, Gravemeyer J, Spassova I, Muminova S, Gambichler T, et al. The HDAC Inhibitor Domatinostat Promotes Cell-Cycle Arrest, Induces Apoptosis, and Increases Immunogenicity of Merkel Cell Carcinoma Cells. J Invest Dermatol (2020) S0022-202X:32074-1. doi: $10.1016 /$ j.jid.2020.08.023

73. Han Y, Liu D, Li L. PD-1/PD-L1 Pathway: Current Researches in Cancer. Am J Cancer Res (2020) 10:727.

74. Terheyden P, Becker JC. New Developments in the Biology and the Treatment of Metastatic Merkel Cell Carcinoma. Curr Opin Oncol (2017) 29:221-6. doi: 10.1097/CCO.0000000000000363

75. Sun JY, Zhang D, Wu S, Xu M, Zhou X, Lu XJ, et al. Resistance to PD-1/PDL1 Blockade Cancer Immunotherapy: Mechanisms, Predictive Factors, and Future Perspectives. Biomark Res (2020) 8:1-10. doi: 10.1186/S40364-02000212-5/FIGURES/1

76. Lei Q, Wang D, Sun K, Wang L, Zhang Y. Resistance Mechanisms of AntiPD1/PDL1 Therapy in Solid Tumors. Front Cell Dev Biol (2020) 8:672/ BIBTEX. doi: 10.3389/FCELL.2020.00672/BIBTEX

77. Ugurel S, Spassova I, Wohlfarth J, Drusio C, Cherouny A, Melior A, et al. MHC Class-I Downregulation in PD-1/PD-L1 Inhibitor Refractory Merkel Cell Carcinoma and Its Potential Reversal by Histone Deacetylase Inhibition: A Case Series. Cancer Immunol Immunother (2019) 68:983-90. doi: 10.1007/ s00262-019-02341-9

78. Wang Q, Ma S, Song N, Li X, Liu L, Yang S, et al. Stabilization of Histone Demethylase PHF8 by USP7 Promotes Breast Carcinogenesis. J Clin Invest (2016) 126:2205-20. doi: 10.1172/JCI85747

79. Goyama S, Nitta E, Yoshino T, Kako S, Watanabe-Okochi N, Shimabe M, et al. EVI-1 Interacts With Histone Methyltransferases SUV39H1 and G9a for Transcriptional Repression and Bone Marrow Immortalization. Leukemia (2010) 24:81-8. doi: 10.1038/leu.2009.202

80. Du J, Johnson LM, Jacobsen SE, Patel DJ. DNA Methylation Pathways and Their Crosstalk With Histone Methylation. Nat Rev Mol Cell Biol (2015) 16:519-32. doi: $10.1038 / \mathrm{nrm} 4043$

81. Harms KL, Chubb H, Zhao L, Fullen DR, Bichakiian CK, Johnson TM, et al. Increased Expression of EZH2 in Merkel Cell Carcinoma Is Associated With Disease Progression and Poorer Prognosis. Hum Pathol (2017) 67:78-84. doi: 10.1016/j.humpath.2017.07.009 
82. Hsieh Iy, He J, Wang L, Lin B, Liang Z, Lu B, et al. H3K27me3 Loss Plays a Vital Role in CEMIP Mediated Carcinogenesis and Progression of Breast Cancer With Poor Prognosis. BioMed Pharmacother (2020) 123:109728. doi: 10.1016/j.biopha.2019.109728

83. Juan AH, Wang S, Ko KD, Zare H, Tsai PF, Feng X, et al. Roles of H3K27me2 and H3K27me3 Examined During Fate Specification of Embryonic Stem Cells. Cell Rep (2016) 17:1369-82. doi: 10.1016/ j.celrep.2016.09.087

84. Sheng W, LaFleur MW, Nguyen TH, Chen S, Chakravarthy A, Conway JR, et al. LSD1 Ablation Stimulates Anti-Tumor Immunity and Enables Checkpoint Blockade. Cell (2018) 174:549-63. doi: 10.1016/ j.cell.2018.05.052

85. Cao R, Wang L, Wang H, Xia L, Erdjument-Bromage H, Tempst P, et al. Role of Histone H3 Lysine 27 Methylation in Polycomb-Group Silencing. Science (2002) 298:1039-43. doi: 10.1126/SCIENCE.1076997

86. Nicetto D, Zaret KS. Role of H3K9me3 Heterochromatin in Cell Identity Establishment and Maintenance. Curr Opin Genet Dev (2019) 55:1-10. doi: 10.1016/J.GDE.2019.04.013

87. Rosenfeld JA, Wang Z, Schones DE, Zhao K, DeSalle R, Zhang MQ. Determination of Enriched Histone Modifications in Non-Genic Portions of the Human Genome. BMC Genomics (2009) 10:143. doi: 10.1186/14712164-10-143

88. Margueron R, Reinberg D. The Polycomb Complex PRC2 and Its Mark in Life. Nat 2011 (2011) 469:343-9. doi: 10.1038/nature09784. 4697330.

89. Santos-Rosa H, Schneider R, Bernstein BE, Karabetsou N, Morillon A, Weise C, et al. Methylation of Histone H3 K4 Mediates Association of the Iswlp ATPase With Chromatin. Mol Cell (2003) 12:1325-32. doi: 10.1016/S10972765(03)00438-6

90. Cheng J, Park DE, Berrios C, White EA, Arora R, Yoon R, et al. Merkel Cell Polyomavirus Recruits MYCL to the EP400 Complex to Promote Oncogenesis. PLoS Pathog (2017) 13:e1006668. doi: 10.1371/journal.ppat. 1006668

91. Park DE, Cheng J, McGrath JP, Lim MY, Cushman C, Swanson SK, et al. Merkel Cell Polyomavirus Activates LSD1-Mediated Blockade of nonCanonical BAF to Regulate Transformation and Tumorigenesis. Nat Cell Biol (2020) 22:603-15. doi: 10.1038/s41556-020-0503-2

92. Mauri F, Blanpain C. Targeting the Epigenetic Addiction of Merkel Cell Carcinoma. EMBO Mol Med (2020) 12:e13347. doi: 10.15252/emmm. 202013347

93. Harms PW, Harms KL, Moore PS, DeCaprio JA, Nghiem P, Wong MKK, et al. The Biology and Treatment of Merkel Cell Carcinoma: Current Understanding and Research Priorities. Nat Publishing Group (2018) 15:763-76. doi: 10.1038/s41571-018-0103-2

94. Veija T, Koljonen V, Bohling T, Kero M, Knuutila S, Sarhadi VK. Aberrant Expression of ALK and EZH2 in Merkel Cell Carcinoma. BMC Cancer (2017) 17:1-9. doi: 10.1186/s12885-017-3233-5

95. Marchione DM, Lisby A, Viaene AN, Santi M, Nasrallah ML, Wang LP, et al. Histone H3K27 Dimethyl Loss is Highly Specific for Malignant Peripheral Nerve Sheath Tumor and Distinguishes True PRC2 Loss From Isolated H3K27 Trimethyl Loss. Mod Pathol (2019) 32:1434-44. doi: 10.1038/ s41379-019-0287-8

96. Laugesen A, Højfeldt JW, Helin K. Role of the Polycomb Repressive Complex 2 (PRC2) in Transcriptional Regulation and Cancer. Cold Spring Harb Perspect Med (2016) 6(9):a026575. doi: 10.1101/cshperspect.a026575

97. Orouji E, Peitsch WK, Orouji A, Houben R, Utikal J. Unique Role of Histone Methyltransferase Prdm8 in the Tumorigenesis of Virus-Negative Merkel Cell Carcinoma. Cancers (Basel) (2020) 12:1057. doi: 10.3390/ cancers 12041057

98. Fernandez-Capetillo O, Allis CD, Nussenzweig A. Phosphorylation of Histone H2B at DNA Double-Strand Breaks. J Exp Med (2004) 199:16717. doi: $10.1084 / \mathrm{jem} .20032247$

99. Metzger E, Yin N, Wissmann M, Kunowska N, Fischer K, Friedrichs N, et al. Phosphorylation of Histone $\mathrm{H} 3$ at Threonine 11 Establishes a Novel
Chromatin Mark for Transcriptional Regulation. Nat Cell Biol (2008) 10:53-60. doi: 10.1038/ncb1668

100. Basnet H, Su XB, Tan Y, Meisenhelder J, Merkurjev D, Ohgi KA, et al. Tyrosine Phosphorylation of Histone H2A by CK2 Regulates Transcriptional Elongation. Nature (2014) 516:267-71. doi: 10.1038/nature13736

101. Polioudaki H, Markaki Y, Kourmouli N, Dialynas G, Theodoropoulos PA, Singh PB, et al. Mitotic Phosphorylation of Histone $\mathrm{H} 3$ at Threonine 3. FEBS Lett (2004) 560:39-44. doi: 10.1016/S0014-5793(04)00060-2

102. Cook PJ, Ju BG, Telese F, Wang X, Glass CK, Rosenfeld MG. Tyrosine Dephosphorylation of H2AX Modulates Apoptosis and Survival Decisions. Nature (2009) 458:591-6. doi: 10.1038/nature07849

103. Henderson SA, Tetzlaff MT, Pattanaprichakul P, Fox P, Torres-Cabala CA, Bassett RL, et al. Detection of Mitotic Figures and G2+ Tumor Nuclei With Histone Markers Correlates With Worse Overall Survival in Patients With Merkel Cell Carcinoma. J Cutan Pathol (2014) 41:846-52. doi: 10.1111/ cup. 12383

104. Wu JH, Narayanan D, Limmer AL, Simonette RA, Rady PL, Tyring SK. Merkel Cell Polyomavirus Small T Antigen Induces DNA Damage Response. Intervirology (2019) 62:96-100. doi: 10.1159/000501419

105. Kotowski U, Erović BM, Schnöll J, Stanek V, Janik S, Steurer M, et al. Quantitative Proteome Analysis of Merkel Cell Carcinoma Cell Lines Using SILAC. Clin Proteomics (2019) 16:42. doi: 10.1186/s12014-019-9263-z

106. Neagu M, Constantin C, Cretoiu SM, Zurac S. miRNAs in the Diagnosis and Prognosis of Skin Cancer. Front Cell Dev Biol (2020) 8:71. doi: 10.3389/ fcell.2020.00071

107. Banerjee M. Pharmacoepigenomics: A Key Determinant in Resolving Epigenomic Parameters in Pathogenesis, and Treatment Response in Complex Diseases. (2021) 23(2):81-4. doi: 10.2217/PGS-2021-0140

108. Lee P, Yim R, Yung Y, Chu HT, Yip PK, Gill H. Molecular Targeted Therapy and Immunotherapy for Myelodysplastic Syndrome. Int J Mol Sci (2021) 22:10232. doi: 10.3390/IJMS221910232

109. Young CS, Clarke KM, Kettyle LM, Thompson A, Mills KI, Young CS, et al. Decitabine-Vorinostat Combination Treatment in Acute Myeloid Leukemia Activates Pathways With Potential for Novel Triple Therapy. Oncotarget (2017) 8:51429-46. doi: 10.18632/ONCOTARGET.18009

110. Ungerstedt JS. Epigenetic Modifiers in Myeloid Malignancies: The Role of Histone Deacetylase Inhibitors. Int J Mol Sci (2018) 19:3091. doi: 10.3390/ IJMS19103091

111. Santini V, Lübbert M, Wierzbowska A, Ossenkoppele GJ, Ther A. The Clinical Value of Decitabine Monotherapy in Patients With Acute Myeloid Leukemia. Adv Ther (2021) 1:1-15. doi: 10.1007/S12325-021-01948-8

112. Vincenzi F, Rotondo JC, Pasquini S, Di Virgilio F, Varani K, Tognon M. A3 Adenosine and P2X7 Purinergic Receptors as New Targets for an Innovative Pharmacological Therapy of Malignant Pleural Mesothelioma. Front Oncol (2021) 11:679285/BIBTEX. doi: 10.3389/FONC.2021.679285/BIBTEX

Conflict of Interest: The authors declare that the research was conducted in the absence of any commercial or financial relationships that could be construed as a potential conflict of interest.

Publisher's Note: All claims expressed in this article are solely those of the authors and do not necessarily represent those of their affiliated organizations, or those of the publisher, the editors and the reviewers. Any product that may be evaluated in this article, or claim that may be made by its manufacturer, is not guaranteed or endorsed by the publisher.

Copyright () 2022 Mazziotta, Lanzillotti, Gafà, Touzé, Durand, Martini and Rotondo. This is an open-access article distributed under the terms of the Creative Commons Attribution License (CC BY). The use, distribution or reproduction in other forums is permitted, provided the original author(s) and the copyright owner(s) are credited and that the original publication in this journal is cited, in accordance with accepted academic practice. No use, distribution or reproduction is permitted which does not comply with these terms. 